\title{
Hexabromocyclododecanes (HBCDDs) in surface soils from coastal cities in North China: Correlation between diastereoisomer profiles and industrial activities
}

\author{
Yueqing Zhang a, b, Qifeng Li ${ }^{\text {a, b }}$, Yonglong Lu ${ }^{\text {a, *, Kevin Jones }}{ }^{\text {c }}$, Andrew J. Sweetman ${ }^{\text {c, d }}$ \\ a State Key Lab of Urban and Regional Ecology, Research Center for Eco-Environmental Sciences, Chinese Academy of Sciences, Beijing 100085, China \\ ${ }^{\mathrm{b}}$ University of Chinese Academy of Sciences, Beijing 100049, China \\ ${ }^{c}$ Lancaster Environment Centre, Lancaster University, Lancaster LA1 4YQ UK \\ ${ }^{\mathrm{d}}$ Centre for Ecology \& Hydrology, Wallingford, OX10 8BB, UK
}

\section{H I G H L I G H T S}

- Large scale investigation of HBCDD in soils from 21 cities of China.

- Correlation between diastereoisomer composition in soils and industrial activities.

- Highest concentration was detected in HBCDD production area in Weifang City.

- $\alpha$-HBCDD as predominant diastereoisomer in soil was found in Cangzhou City.

\section{A R T I C L E I N F O}

\section{Article history:}

Received 23 October 2015

Received in revised form

11 January 2016

Accepted 13 January 2016

Available online 4 February 2016

Handling Editor: Myrto Petreas

\section{Keywords:}

HBCDD

Brominated flame retardant

Soil pollution

Emission source

Bohai sea

Yellow sea
G R A P H I C A L A B S T R A C T

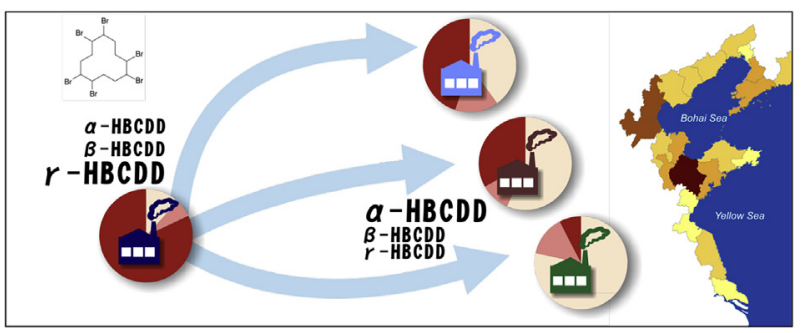

\section{A B S T R A C T}

Hexabromocyclododecane (HBCDD) is a brominated flame retardant with a wide range of industrial applications, although little is known about its patterns of spatial distribution in soils in relation to industrial emissions. This study has undertaken a large-scale investigation around an industrialized coastal area of China, exploring the concentrations, spatial distribution and diastereoisomer profiles of HBCDD in 188 surface soils from 21 coastal cities in North China. The detection frequency was $100 \%$ and concentrations of total HBCDD in the surface soils ranged from 0.123 to $363 \mathrm{ng} \mathrm{g}^{-1}$ and averaged $7.20 \mathrm{ng} \mathrm{g}^{-1}$, showing its ubiquitous existence at low levels. The spatial distribution of HBCDD exhibited a correlation with the location of known manufacturing facilities in Weifang, suggesting the production of HBCDD as major emission source. Diastereoisomer profiles varied in different cities. Diastereoisomer compositions in soils were compared with emissions from HBCDD industrial activities, and correlations were found between them, which has the potential for source identification. Although the contemporary concentrations of HBCDD in soils from the study were relatively low, HBCDD-containing products (expanded/ extruded polystyrene insulation boards) would be a potential source after its service life, and attention needs to be paid to prioritizing large-scale waste management efforts.

() 2016 Elsevier Ltd. All rights reserved.

\footnotetext{
* Corresponding author.

E-mail address: yllu@rcees.ac.cn (Y. Lu).
}

\section{Introduction}

Hexabromocyclododecane (HBCDD) is used as an additive flame retardant mainly in expanded polystyrene (EPS) and extruded 
polystyrene (XPS) foam for thermal insulation in buildings and transport vehicles. It is also used on cotton or mixed blend textiles as a back-coating and in high impact polystyrene (HIPS) applications for use in electric and electronic equipment, albeit at lower volumes (POPRC, 2010). As a result of its widespread usage, HBCDD has become an important alternative brominated flame retardant after the production and use of PBDEs were restricted. In 2001, the global market demand for HBCDD was 16,500 tons (POPRC, 2011), while the estimated global production of HBCDD increased to 31,000 tons in 2011 (POPRC, 2012).

HBCDD can enter the environment via releases to air and wastewater/surface water, during the production and micronising of HBCDD, formulation of EPS, XPS and polymer dispersion, industrial use of EPS, XPS, HIPS and textiles (back-coating), professional use of insulation boards, and service life of textiles (washing and wear), EPS and XPS. Furthermore, HBCDD can directly enter the soil through landfill of end of life articles and demolition materials (European Commission, 2008). HBCDD has been widely detected in the environment (Covaci et al., 2006).

HBCDD has 16 stereoisomers in theory, but commercial technical HBCDD mainly consists of three diastereoisomers, $\alpha$-HBCDD (10-13\%), $\beta$-HBCDD (1-12\%) and $\gamma$-HBCDD (75-89\%), depending on the manufacture and production method. Another two stereoisomers, $\varepsilon$ - and $\delta$-HBCDD, have been detected at low concentrations (Heeb et al., 2005). The composition of HBCDD diastereoisomers could be affected by thermal isomeric rearrangement during product processing and by abiotic/biotic transformation in the environment, which may lead to a different composition from the original technical HBCDD (Covaci et al., 2006; Gerecke et al., 2006; Harrad et al., 2009a; Heeb et al., 2010).

In China, 18000 tons of HBCDD were produced in 2011, more than half of the global production, in which 5500-6000 tons was exported, 9000 tons was applied in EPS and 3000 tons was applied in XPS (POPRC, 2012). Attention has been paid to HBCDD contamination in China, and investigations have been conducted near point-source sites or in the most industrialized cities where concentrations in environmental media have been shown to be relatively high (Yu et al., 2008a; Gao et al., 2011; Li et al., 2012; Zhang et al., 2013; Zhu et al., 2014). A larger scale investigation into HBCDD concentrations and spatial distribution is necessary in order to better understand the contamination status, identify sources, and ultimately reduce associated impacts.

Rapid industrialization and urbanization in China's coastal cities has resulted in both economic growth and environmental pollution from a range of anthropogenic activities. Such intensive industries have been reported to be sources of heavy metals, legacy POPs and novel POPs to regional environments (Hu et al., 2010; Wang et al., 2012; Luo et al., 2013; Meng et al., 2015). The north coast around the Bohai Sea and Yellow Sea in China was investigated in this study, including 21 coastal cities in 5 provinces (Jiangsu Province, Shandong Province, Hebei Province, Liaoning Province, and Tianjin Municipality). HBCDD production facilities are mostly distributed in the coastal areas of Shandong, Hebei and Jiangsu Provinces. Except for raw HBCDD production, brominated flame retardant manufacture, EPS and XPS board processing, flame retardant textile processing, electric and electronic component production, e-waste recycling industries are all located in this region, which are potential sources of HBCDD release. It is also an important agricultural region where arable crops, vegetables and fruits are produced/ cultivated at large scale, while HBCDD can be absorbed by plants (Wu et al., 2012; Zhang et al., 2013). Therefore, the monitoring of HBCDD contaminants in soils is necessary to ensure food safety.

The objectives of this study were to investigate the occurrence, spatial distribution, and diastereoisomer profiles of HBCDD in soils from the coastal cities in North China. Correlations between HBCDD contamination and industrial activities in the region were analyzed to identify potential sources.

\section{Materials and methods}

\subsection{Sample collection}

The sampling campaign was conducted in 21 cities from 5 provinces (Liaoning, Hebei, Tianjin, Shandong, Jiangsu) covering a total area of 213,000 $\mathrm{km}^{2}$ along the China's coast of Bohai and Yellow Seas in September 2013 (Fig. S1). A total of 188 surface (top $0-10 \mathrm{~cm}$ ) soil samples were collected (detailed information in SI).

\subsection{Reagent and standards}

Solvents used in extraction and analysis procedures were HPLCgrade and purchased from Fisher. Silica gel $60(63-100 \mu \mathrm{m})$ were purchased from Merck. Individual standard stock solutions $(\alpha-$ HBCDD, $\beta$-HBCDD, $\gamma$-HBCDD, C13- $\gamma$-HBCDD, d18- $\gamma$-HBCDD) were obtained from Wellington Laboratories (Canada) with concentration of $50 \mu \mathrm{g} \mathrm{mL}^{-1}$ in toluene with purity $>98 \%$.

\subsection{Extraction and cleanup}

Sample extraction followed the procedure described in Harrad et al., 2009b with some modifications. $10 \mathrm{~g}$ accurately weighed soil (mixed with $15 \mathrm{~g}$ pre-heated anhydrous sodium sulfate) were spiked with $10 \mathrm{ng}$ of $\mathrm{C} 13-\gamma$-HBCDD as surrogate standard and were extracted using ASE 350 with hexane/dichloromethane $(1: 9, \mathrm{v} / \mathrm{v})$ at $90{ }^{\circ} \mathrm{C}$ and 1500 psi (heating time $5 \mathrm{~min}$, static time $4 \mathrm{~min}$, purge time $90 \mathrm{~s}$, flush volume $50 \%$, static cycle 3 ). The concentrated extract was then loaded onto a multi-layer silica gel column (15 mm I.D.) for purification, filled from bottom to top with $1 \mathrm{~g}$ of anhydrous sodium sulfate $\left(500{ }^{\circ} \mathrm{C}\right.$ for $\left.6 \mathrm{~h}\right), 1 \mathrm{~g}$ activated silica gel $\left(130{ }^{\circ} \mathrm{C}\right.$ for $\left.16 \mathrm{~h}\right), 2 \mathrm{~g}$ of Florisil $\left(130{ }^{\circ} \mathrm{C}\right.$ for $4 \mathrm{~h}$ ), $1 \mathrm{~g}$ activated silica gel, $3 \mathrm{~g}$ of basic silica gel $(2 \%, \mathrm{w} / \mathrm{w}), 1 \mathrm{~g}$ activated silica gel, $8 \mathrm{~g}$ of acid silica gel $(44 \%, \mathrm{w} / \mathrm{w}), 1 \mathrm{~g}$ activated silica gel, $1 \mathrm{~g}$ of anhydrous sodium sulfate. The column was wet-filled with hexane. Analytes were eluted with $120 \mathrm{~mL}$ hexane/dichloromethane $(1: 1, \mathrm{v} / \mathrm{v})$. The eluate was concentrated by a rotary evaporator to $1-2 \mathrm{~mL}$ and further evaporated to incipient dryness under $\mathrm{N}_{2}$, and reconstituted in $200 \mu \mathrm{L}$ of methanol/water $(8: 2, \mathrm{v} / \mathrm{v})$ containing $10 \mathrm{ng}$ of $\mathrm{d} 18-\gamma-$ $\mathrm{HBCDD}$ as recovery determination standard.

\subsection{Instrumental analysis}

The analysis of HBCDD was performed on Agilent 1290 UPLC system coupled to Agilent 6460 triple quadruple tandem mass spectrometry. Separation was performed on an Aglient Eclipse Plus C18 column $(2.1 \times 100 \mathrm{~mm}, 1.8 \mu \mathrm{m})$ (detailed description in SI).

\section{5. $Q A / Q C$}

Quantification was carried out by an isotopic dilution technique. C13- $\gamma$-HBCDD was used as a surrogate standard for HBCDD quantification, and $\mathrm{d} 18-\gamma-\mathrm{HBCDD}$ was used for C13- $\gamma$-HBCDD recovery evaluation for each sample. The calibration curve was derived using a series of standards ranging from 2 to $500 \mathrm{ng} \mathrm{mL}^{-1}$ and fixed concentrations $\left(50 \mathrm{ng} \mathrm{mL}^{-1}\right)$ of the internal standards $\left(\mathrm{r}^{2}>0.999\right)$. A procedural blank (anhydrous $\mathrm{Na}_{2} \mathrm{SO}_{4}$ ) was added within each batch of 12 samples to assess possible contamination. These were all below LOD. Spiking-recovery tests were conducted using soil (preheated at $550{ }^{\circ} \mathrm{C}$ for $12 \mathrm{~h}$ ) spiked with $10 \mathrm{ng}$ each of native HBCDD before extraction and analysis. The mean recoveries $(n=7)$ of individual HBCDD isomers were $69 \pm 8 \%$ for $\alpha$-HBCDD, $67 \pm 6 \%$ 
for $\beta$-HBCDD and $66 \pm 12 \%$ for $\gamma$-HBCDD.

\section{Results and discussion}

\section{1. $H B C D D$ levels in soils}

For individual diastereoisomers, detection frequencies were $97.3 \%, 97.9 \%$ and $100 \%$ for $\alpha-, \beta-$ and $\gamma$-HBCDD, respectively. Concentration ranges were ND-49.3 $\mathrm{ng} \mathrm{g}^{-1}$ (average $2.02 \mathrm{ng} \mathrm{g}^{-1}$ ) for $\alpha$ HBCDD, ND-30.0 $\mathrm{ng} \mathrm{g}^{-1}$ (average $0.800 \mathrm{ng} \mathrm{g}^{-1}$ ) for $\beta$-HBCDD, and $0.052-284 \mathrm{ng} \mathrm{g}^{-1}$ (average $4.38 \mathrm{ng} \mathrm{g}^{-1}$ ) for $\gamma$-HBCDD. All concentrations were presented in dry weight. $\Sigma$ HBCDD was detected in all 188 soil samples ( $\alpha$-HBCDD in 183 samples, $\beta$-HBCDD in 184 samples and $\gamma$-HBCDD in all samples, respectively) and ranged from 0.123 to $363 \mathrm{ng} \mathrm{g}^{-1}$ with a mean value of $7.20 \mathrm{ng} \mathrm{g}^{-1}$, suggesting HBCDD's ubiquitous existence along the north coast of Bohai and Yellow seas in China. Among the 188 samples, in terms of HBCDD concentration, 2 samples were higher than $100 \mathrm{ng} \mathrm{g}^{-1}, 17$ samples ranged $10-100 \mathrm{ng} \mathrm{g}^{-1}, 93$ samples ranged $1-10 \mathrm{ng} \mathrm{g}^{-1}$, and the remaining 76 samples were all below $1 \mathrm{ng} \mathrm{g}^{-1}$, showing an overall low level of contamination (Fig. S3). HBCDD levels had no significant difference under different types of land use.

Reports of HBCDD concentration distributions in surface soils are scarce, especially at such a large scale. Early investigations of HBCDD in soils were focused on point-sources such as HBCDD manufacturing and processing sites. In areas containing possible point sources, HBCDD concentrations exceeded thousands of ng $^{-1}$, such as the soils from HBCDD manufacturing plants in China which ranged from 0.88 to $6901 \mathrm{ng} \mathrm{g}^{-1}$ (Li et al., 2012), and XPS producing plant in Sweden ranged from 140 to $1300 \mathrm{ng} \mathrm{g}^{-1}$ (Remberger et al., 2004). Concentrations in these areas were one order of magnitude higher than those from this study, and similar to those from e-waste recycling areas $\left(0.01-284 \mathrm{ng} \mathrm{g}^{-1}\right)$ in Guangzhou City (Gao et al., 2011) and a BFR-manufacturing region $\left(0.30-280 \mathrm{ng} \mathrm{g}^{-1}\right.$ ) in Shouguang (Zhu et al., 2014) (a county of Weifang City). HBCDD levels in soils from non-point source areas were only reported in China, with concentrations ranging from 0.17 to $34.5 \mathrm{ng} \mathrm{g}^{-1}$ in agricultural soils in rural areas of Beijing (Thanh et al., 2013), Nd-0.094 $\mathrm{ng} \mathrm{g}^{-1}$ in rural areas of Shanghai (Meng et al., 2011), 1.7-5.6 $\mathrm{ng} \mathrm{g}^{-1}$ in urban areas of Guangzhou (Yu et al., 2008b), and $0.03-29.9 \mathrm{ng} \mathrm{g}^{-1}$ in industrial soils from 5 cities in Guangdong Province (Gao et al., 2011). These concentrations were one magnitude lower than those in point source areas. In this study, more than $90 \%$ of the samples were within the range of nonpoint source areas, while in Rizhao, Weihai and Panjin Cities, HBCDD exhibited overall low concentrations below $1 \mathrm{ng} \mathrm{g}^{-1}$.

\subsection{Spatial distribution}

Average HBCDD concentrations in surface soils collected from 21 cities (Table S2) varied in spatial distribution with the highest values of 34.6, 12.3, $11.1 \mathrm{ng} \mathrm{g}^{-1}$ detected in Weifang, Cangzhou, and Tianjin, respectively. 18 other cities showed lower concentrations than $10 \mathrm{ng} \mathrm{g}^{-1}$ and among them 5 cities have concentrations lower than $1 \mathrm{ng} \mathrm{g}^{-1}$. The HBCDD manufacturing facilities that could be identified are presented in Fig. 1. They are mainly located in the cities of Weifang, Cangzhou and Lianyungang. However, HBCDD levels in these three cities varied significantly, which may result from different emission intensities as a result of their different production volumes and histories. The first HBCDD production facility was built in 1999 in Weifang. At present, several facilities have stated annual production capacities in excess of 2000 tons. In Liangyungang, HBCDD production started in 2004 with a relatively low capacity, while in Cangzhou production was negligible. HBCDD in most of the other cities exhibited low concentrations and spatially distributed evenly, which may come from diffuse sources rather than direct industrial sources.

The highest concentrations in this study were found in Weifang. The spatial distribution of HBCDD in Weifang varied significantly with sampling location $(n=19)$ (Fig. 1). The level of the nearest site from WF-19 (with the highest concentration of $363 \mathrm{ng} \mathrm{g}^{-1}$ ), $11 \mathrm{~km}$ away, is only $1.71 \mathrm{ng} \mathrm{g}^{-1}$, suggesting that the contamination was mostly caused by local discharge rather than regional transport, and the concentration decreased dramatically with distance. The decreasing concentration of HBCDD was also reported with increasing distance from the point source up to $8 \mathrm{~km}$ away (Li et al., 2012). In this investigation, even though we sampled at regular intervals in space and did not target any facility or source, higher concentrations were detected at sample sites closer to the manufacturing facilities or other sources.

High concentrations were detected in the northern coast of Weifang, where the Coastal Economic and Technological Development Zone (known as the biggest flame retardant production base in China) is located. The occurrence of HBCDD in soils showed a spatial correlation with HBCDD manufacturing facility, inferred to be the source. These facilities were intensively located in 3 towns, Yangkou, Houzhen and Dajiawa in the northern coast of this city (Fig. 1). WF-19 (363 $\mathrm{ng} \mathrm{g}^{-1}$ ) was sampled in an agricultural region in the east of Dajiawa Town, $2.6 \mathrm{~km}$ away from a manufacturing facility with a production capacity of 3000 ton/a to the northeast (Weifang Environmental Protection Bureau, 2015), which should be the direct emission source in this area. WF-03 (159 $\left.\mathrm{ng} \mathrm{g}^{-1}\right)$ was sampled in an industrial land in the west of Dajiawa Town, but there was no manufacturing facility found as direct source. The nearest potential source was Houzhen Industrial Zone, $10 \mathrm{~km}$ away in the southeast, where more than 3 manufacturing facilities are located.

In Cangzhou, the highest level was detected in its southeast part with a concentration of $53.1 \mathrm{ng} \mathrm{g}^{-1}$. However, manufacturing facilities in Cangzhou are located more than $40 \mathrm{~km}$ away from this sampling site, which may not be the source for this site. In Tianjin, another city with relative high HBCDD concentrations in the soil, no HBCDD manufacturing has been reported. It is therefore possible that HBCDD may be discharged and transported from other sources in Cangzhou and Tianjin.

\subsection{Diastereoisomer profiles}

Diastereoisomer profiles of HBCDD in different cities are shown in Fig. 2. $\alpha$-HBCDD ranged from $10.6 \%$ to $74.4 \%$, $\beta$-HBCDD from $3.3 \%$ to $26.9 \%$, and $\gamma$-HBCDD from $10.6 \%$ to $82.3 \%$. The $\beta$-HBCDD contribution to the total remained constant whilst $\alpha$-HBCDD and $\gamma$ HBCDD varied with $\alpha$-HBCDD's proportion increasing and $\gamma$ HBCDD's decreasing at some sites. Among the 21 cities, 12 cities exhibited similar composition of commercial technical products, which were composed of 70 to $89 \% \gamma$-HBCDD and 11 to $30 \% \alpha$ - and $\beta$-HBCDD (Covaci et al., 2006; Marvin et al., 2011), while 8 cities had $\gamma$-HBCDD ranging from 40 to $60 \%$ and only 1 city (Cangzhou) had $\gamma$ HBCDD below $40 \%$.

There have been only a few investigations on diastereoisomer profiles in soils which have been mainly conducted in China. In some early investigations of HBCDD in environmental media, gas chromatography was used for instrumental analysis, which could not separate the HBCDD isomers, so the results were reported as total concentrations of HBCDD isomers without concentrations or percentages of individual diastereoisomers. In soils from the manufacturing area in China, $\gamma$-HBCDD (67.3\%) was the most abundant diastereoisomer followed by $\alpha$ - and $\beta$-HBCDD with proportions of $20.4 \%, 12.3 \%$ respectively, which was very close to the composition of commercial HBCDD product (Li et al., 2012). 


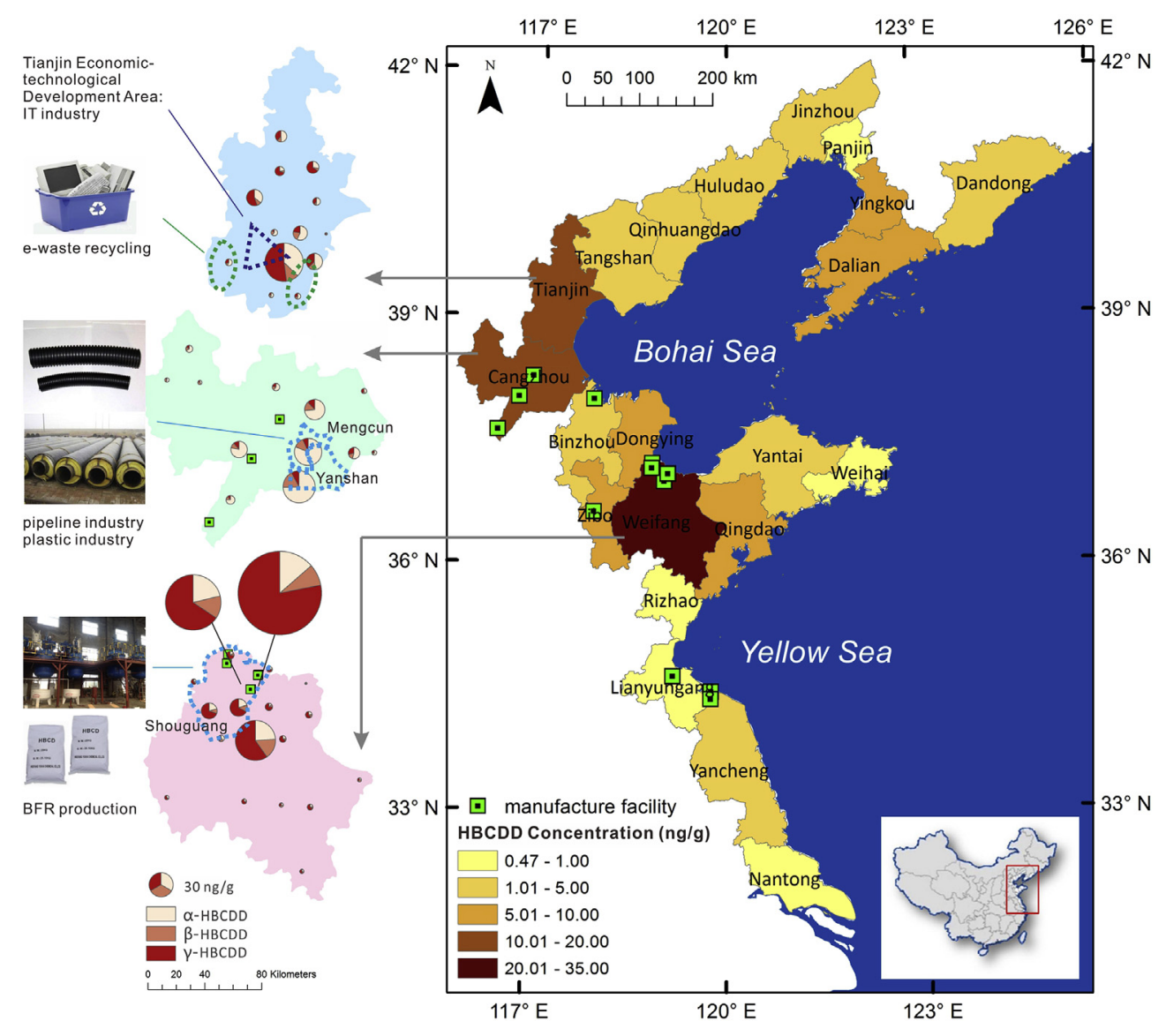

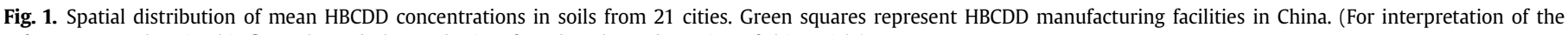
references to colour in this figure legend, the reader is referred to the web version of this article).

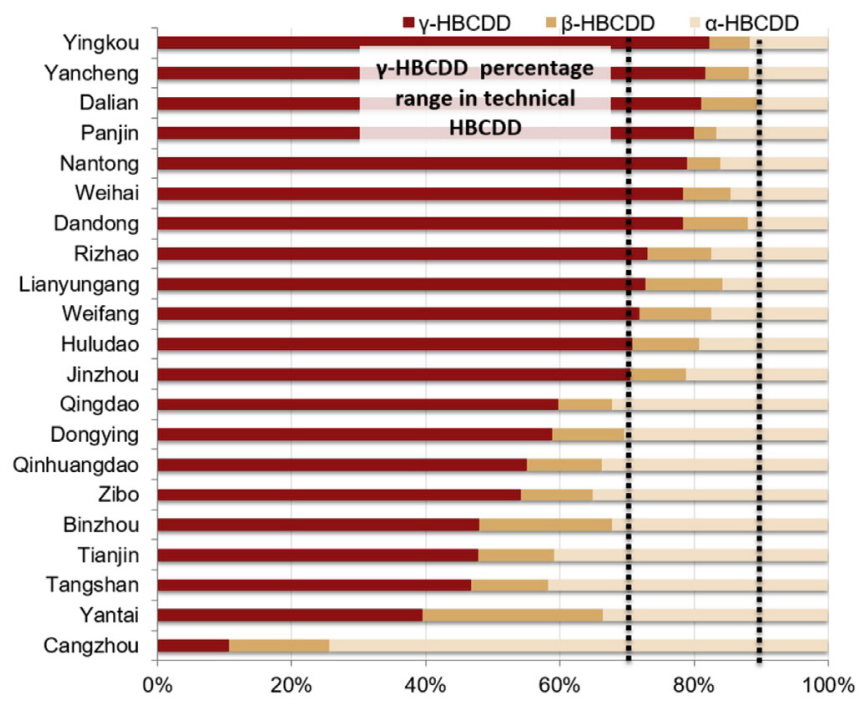

Fig. 2. Diastereoisomer composition of $\mathrm{HBCDD}$ in 21 cities. The dotted line represents the $\gamma$-HBCDD percentage range (70-89\%) in commercial technical HBCDD.

Diastereoisomer composition in point-source sites (11.5\% $\alpha$-HBCDD, $23.2 \% \beta$-HBCDD, $65.3 \% \gamma$-HBCDD) were different from those in nonpoint-source sites (23.8\% $\alpha$-HBCDD, 19.7\% $\beta$-HBCDD, $56.4 \% \gamma$ HBCDD) (Zhu et al., 2014). In surface soils from two e-waste recycling sites in south China, $\gamma$-HBCDD proportion ranged from 40 to
$50 \%$, which was similar to $\alpha$-HBCDD (50-40\%) (excluding data from the industrial area) (Gao et al., 2011). $\gamma$-HBCDD's predominance was reported in rural area in Beijing (Thanh et al., 2013) and Shanghai (Meng et al., 2011), but the ratio of $\gamma$-HBCDD in Beijing (59\%) was relatively low compared to Shanghai (70\%). The variation of diastereoisomer profiles in soils was also reported in South Asian countries (Eguchi et al., 2013).

In contrast, HBCDD diastereoisomer profiles showed a predominance of $\alpha$-HBCDD in birds' tissues/eggs (Guerra et al., 2012), fish (Xia et al., 2011; Meng et al., 2012), mollusks (Zhu et al., 2012), ringed seals (Vorkamp et al., 2011) and other biota, suggesting the impact of environmental processes on the change of diastereoisomer contribution.

\subsection{Relations with industrial activities}

Relatively high concentrations found in soils from Weifang, Cangzhou and Tianjin, coupled with different diastereoisomer contributions to the total concentrations would indicate the existence of a range of emission sources. Diastereoisomer profiles and their associations with industrial activities were observed (Fig. 3). Besides the formulation of raw HBCDD product, HBCDD could also enter the environment via atmospheric deposition, wastewater discharge, and landfill of waste in the life cycle of EPS/XPS insulation boards, electric and electronic appliances (plastic shell, wire and cable), and textile back-coatings. Industrial activities, especially extrusion molding and thermal cutting, could change the diastereoisomer composition in HBCDD-containing products and the composition in the environmental media through industrial 


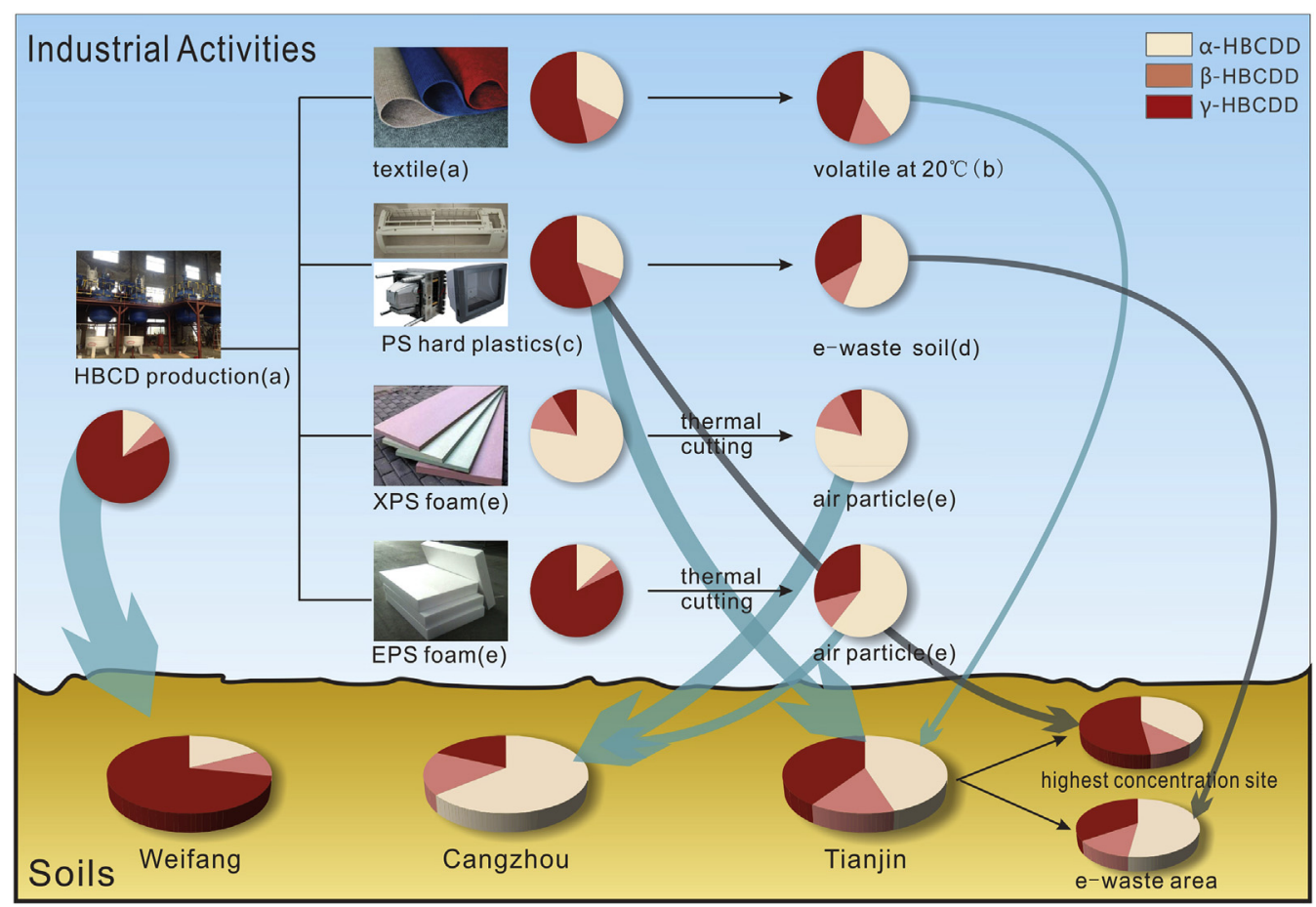

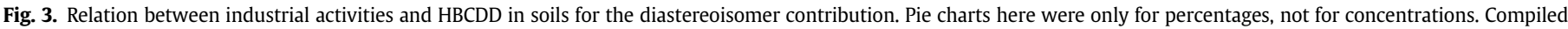
from a, Kajiwara et al. (2009); b, Kajiwara and Takigami (2013); c, Rani et al. (2014); d, Gao et al. (2011); e, Zhang et al. (2012).

emission. A significant linear correlation $\left(R^{2}=0.99, \mathrm{p}<0.01\right)$ of the ratio $\gamma$-HBCDD: $\alpha$-HBCDD was found between industrial activities and soils (Fig. 4), indicating that HBCDD diastereoisomer profile in soil was strongly impacted by industrial emissions.

In Weifang, the diastereoisomer contribution ranged from $13.6 \%$ to $37.6 \%$ for $\alpha$-HBCDD, from $8.3 \%$ to $31.4 \%$ for $\beta$-HBCDD, and from $32.9 \%$ to $78.1 \%$ for $\gamma$-HBCDD, and averaged $17.4 \%, 10.8 \%, 71.8 \%$ respectively. The composition, especially in the BFR production area in Shouguang $(16.2 \%, 9.9 \%, 73.9 \%$ for $\alpha-, \beta$ - and $\gamma$-HBCDD

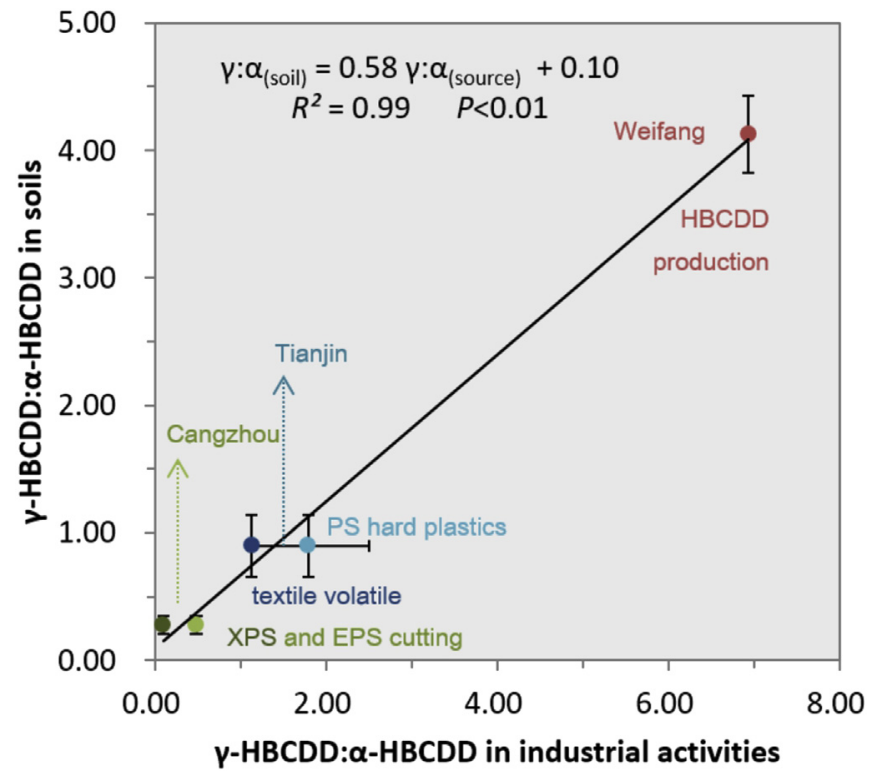

Fig. 4. Correlation of $\gamma$-HBCDD: $\alpha-H B C D D$ ratio between industrial activities and soils. Data of industrial activities was obtained from Kajiwara et al. (2009); Kajiwara and Takigami (2013); Rani et al. (2014); Gao et al. (2011); Zhang et al. (2012). respectively), was consistent with the commercial technical HBCDD product. This was evidence that the contamination of HBCDD in soil was released from adjacent BFR production facilities and the diastereoisomer composition was not changed significantly by natural processes in the environment.

In Cangzhou, $\alpha$-HBCDD was predominant across the whole city ranging from $42.8 \%$ to $81.1 \%$ (averaged $63.9 \%$ ) while $\gamma$-HBCDD ranged from $6.6 \%$ to $41.1 \%$ (averaged $18.0 \%$ ). It was noted that relatively high concentrations $\left(53.1 \mathrm{ng} \mathrm{g}^{-1}\right.$ at CZ-07, $38.7 \mathrm{ng} \mathrm{g}^{-1}$ at CZ-08) were found in Yanshan Town, and that the lowest $\gamma$-HBCDD proportions (6.6\% and 8.0\%) were also detected in Yanshan, known as the Pipeline Equipment Manufacturing Base of China in the southeast of Cangzhou. In this area, metal and plastic pipelines are produced including flame retardant pipe, pipe shell and board. Additionally, a plastics industrial park was also located in this area, and the industrial chain included flame retardant production, plastic pipe and board (mainly XPS) forming and cutting. In 2013, the production of plastic products reached 520,000 tons in Cangzhou (Cangzhou Government, 2013), implying a large market demand for HBCDD.

During the manufacturing process of these plastic products, intense thermal processing could explain the changing HBCDD diastereoisomer contributions. For Polystyrene (PS) consumer products (food container, packing support, etc.) collected in Korea, $\gamma$-HBCDD was the dominant isomer with an average percentage of $56 \%$, which was lower than the original percentage of technical HBCDD. PS hard plastics (general purpose polystyrene, GPPS; high impact polystyrene, HIPS; etc.), which undergo more processing in industry than EPS, contained lower $\gamma$-HBCDD proportion than other materials (Rani et al., 2014). In insulation board, $\gamma$-HBCDD was the predominant component with a similar composition to commercial technical HBCDD product in EPS raw foam, whilst $\alpha$ HBCDD was predominant in XPS raw foam. However, in particles emitted from thermal cutting of both EPS and XPS, $\alpha$-HBCDD was predominant and $\gamma$-HBCDD was only $29 \%$ from EPS and $8 \%$ from 
XPS (Zhang et al., 2012). This proportion of $\gamma$-HBCDD was close to that of Yanshan.

In Tianjin, $\alpha$-HBCDD ranged from $22.9 \%$ to $62.4 \%$ with an average of $45.1 \%$ while $\gamma$-HBCDD ranged from $13.6 \%$ to $69.8 \%$ with an average of $40.6 \%$. A significantly high level of HBCDD, $76.5 \mathrm{ng} \mathrm{g}^{-1}$ at TJ-08, was detected in its south with the other 12 sites lower than $15 \mathrm{ng} \mathrm{g}^{-1}$. It consisted of $37.5 \% \alpha-\mathrm{HBCDD}, 10.4 \% \beta$-HBCDD and $52.1 \%$ $\gamma$-HBCDD. This site was located among a group of small factories including a flame-retardant electric wire plant $3 \mathrm{~km}$ away. To the west of this site was a state-level economic and technology development zone, where integrated circuits, mobile communications equipment, and electronic components were produced, including flame retardant electric wires and cables. Flame retardant EXP, XPS and textile were also produced in the neighboring area.

As shown in Fig. 3, PS hard plastics could be used to make various consumer products like mobile phone holders and computer shells, and it was composed of $31.0 \% \alpha-\mathrm{HBCDD}, 13.5 \% \beta-$ HBCDD and 55.5\% $\gamma$-HBCDD (Rani et al., 2014). The diastereoisomer contribution of Tianjin was similar to the flame-retardant upholstery textiles, which were mainly used for curtain manufacturing. The percentage contributions of $\alpha$-, $\beta$ - and $\gamma$-diastereoisomers to total HBCDDs in textiles were found to be $26-46 \%, 12-18 \%, 38-61 \%$ (Kajiwara et al., 2009). It has been reported that for volatile substances emitted from textiles at different temperatures, the proportion of $\alpha$-HBCDD increased when the temperature increased (Kajiwara and Takigami, 2013). However, the consumption of HBCDD in textile back-coating was negligible, so its impact on isomer profiles was less than PS plastics production. The contamination in Tianjin may be caused by mixed sources, and more investigation is needed to confirm that.

Since high concentrations of HBCDD have been reported in ewaste recycling sites in Southern China, in this study, high levels were also expected to be associated with the biggest e-waste recycling area in Northern China, located in Tianjin. Unexpectedly, the concentrations of HBCDD were only $2.96 \mathrm{ng} \mathrm{g}^{-1}(51.7 \% \alpha-$ HBCDD, 9.9\% $\beta$-HBCDD and 38.4\% $\gamma$-HBCDD) and 1.79 ng g $^{-1}(52.6 \%$ $\alpha$-HBCDD, $16.4 \% \beta$-HBCDD and 31.0\% $\gamma$-HBCDD) respectively in Jinghai County and Dagang District, where the e-waste recycling area is located. In e-waste recycling sites in Southern China, $\gamma$ HBCDD was the predominant isomer (36.3\% $\alpha$-HBCDD, $4.8 \% \beta-$ HBCDD and 58.9\% $\gamma$-HBCDD) in Qingyuan with a total concentration of $106 \mathrm{ng} \mathrm{g}^{-1}$, while $\alpha$-HBCDD was predominant $(56.4 \% \alpha$ HBCDD, $10.3 \% \beta$-HBCDD and 33.3\% $\gamma$-HBCDD) in Guiyu with a total concentration of only $2.34 \mathrm{ng} \mathrm{g}^{-1}$ (Gao et al., 2011). The diastereoisomer profiles in samples from Tianjin in this study were very close to that from Guiyu, suggesting the impact of e-waste recycling as the common source in both areas. In Tianjin the recycling facilities are operated under strict controls with closed operations, which is in contrast to the informal (open) recycling process in Guangzhou which may explain the lower concentrations found in the Northern e-waste recycling center. A study carried out at informal e-waste recycling sites in Vietnam found that $\alpha$-HBCDD was predominant in both dust and air samples collected in the backyard of e-waste recycling houses, and 6 and 10 times more abundant than $\gamma$-HBCDD respectively (Tue et al., 2013). This variation may result from the difference in e-products category and recycling method in the two countries.

Diastereoisomer composition of HBCDD can be affected by environmental factors. $\alpha$-HBCDD has slower degradation kinetics and a longer half-life than $\beta$ - and $\gamma$-HBCDD in activated sludge, digester sludge, freshwater sediments and soils (Davis et al., 2005, 2006bib_Davis_et_al_2006; Gerecke et al., 2006). Photolytically mediated shift under natural light can affect HBCDD composition in indoor dust (Harrad et al., 2009a). However, environmental factors are complex and hard to evaluate, further research is needed to illustrate the variable diastereoisomer profile.

\section{Conclusions}

This study reported the occurrence, spatial distribution and diastereoisomer profiles of HBCDD in surface soils from the coastal cities in North China, and investigated the relation of diastereoisomer ratio between industrial activities and environmental matrix. HBCDD were detected in all the soil samples but the overall level was low, with relatively higher levels found in Weifang, Cangzhou and Tianjin. Although the current levels were relatively low, HBCDD-containing products would become a potential source to discharge HBCDD into the soil. Commercial technical HBCDD manufacture was identified as the main source in Weifang, while XPS and EPS foam processing could be the main source in Cangzhou, and PS hard plastics production, e-waste recycling and textile processing could be the major source in Tianjin. Industrial activities could change the diastereoisomer composition of HBCDD, and strong correlation was found between diastereoisomer composition in soils and emission from local industrial activities. However, uncertainties in this study should be noted, for large scale sampling might bring about information loss for spatial heterogeneity of contaminants, and industrial activity was not the only factor affecting the diastereoisomer composition. Further research is required to illustrate the variable diastereoisomer profile.

\section{Acknowledgments}

This study was supported by the Chinese Academy of Sciences under Grant no. KZZD-EW-TZ-12, the International Scientific Cooperation Program with Grant no. 2012DFA91150, and the National Natural Science Foundation of China under Grant no. 414201040045 and 41371488 . We would like to thank the editors and reviewers for their valuable comments and suggestions.

\section{Appendix A. Supplementary data}

Supplementary data related to this article can be found at http:// dx.doi.org/10.1016/j.chemosphere.2016.01.051.

\section{References}

Cangzhou Government, 2013. Summary of Cangzhou Economics.

Covaci, A., Gerecke, A.C., Law, R.J., Voorspoels, S., Kohler, M., Heeb, N.V., Leslie, H., Allchin, C.R., de Boer, J., 2006. Hexabromocyclododecanes (HBCDs) in the environment and humans: a review. Environ. Sci. Technol. 40, 3679-3688.

Davis, J., Gonsior, S., Marty, G., Ariano, J., 2005. The transformation of hexabromocyclododecane in aerobic and anaerobic soils and aquatic sediments. Water Res. 39, 1075-1084.

Davis, J.W., Gonsior, S.J., Markham, D.A., Friederich, U., Hunziker, R.W., Ariano, J.M., 2006. Biodegradation and product identification of $[14 \mathrm{C}]$ hexabromocyclododecane in wastewater sludge and freshwater aquatic sediment. Environ. Sci. Technol. 40, 5395-5401.

Eguchi, A., Isobe, T., Ramu, K., Tue, N.M., Sudaryanto, A., Devanathan, G., Viet, P.H., Tana, R.S., Takahashi, S., Subramanian, A., Tanabe, S., 2013. Soil contamination by brominated flame retardants in open waste dumping sites in Asian developing countries. Chemosphere 90, 2365-2371.

European Commission, 2008. Risk Assessment Hexabromocyclododecane. CAS-No. 25637-99-4, EINECSNo.: 247-148-4, Final Report May 2008.

Gao, S., Wang, J., Yu, Z., Guo, Q., Sheng, G., Fu, J., 2011. Hexabromocyclododecanes in surface soils from e-waste recycling areas and industrial areas in South China: concentrations, diastereoisomer- and enantiomer-specific profiles, and inventory. Environ. Sci. Technol. 45, 2093-2099.

Gerecke, A.C., Giger, W., Hartmann, P.C., Heeb, N.V., Kohler, H.-P.E., Schmid, P., Zennegg, M., Kohler, M., 2006. Anaerobic degradation of brominated flame retardants in sewage sludge. Chemosphere 64, 311-317.

Guerra, P., Alaee, M., Jimenez, B., Pacepavicius, G., Marvin, C., MacInnis, G., Eljarrat, E., Barcelo, D., Champoux, L., Fernie, K., 2012. Emerging and historical brominated flame retardants in peregrine falcon (Falco peregrinus) eggs from Canada and Spain. Environ. Int. 40, 179-186.

Harrad, S., Abdallah, M.A.-E., Covaci, A., 2009a. Causes of variability in concentrations and diastereomer patterns of hexabromocyclododecanes in indoor dust. 
Environ. Int. 35, 573-579.

Harrad, S., Abdallah, M.A.-E., Rose, N.L., Turner, S.D., Davidson, T.A., 2009b. Currentuse brominated flame betardants in water, sediment, and fish from English lakes. Environ. Sci. Technol. 43, 9077-9083.

Heeb, N.V., Graf, H., Schweizer, W.B., Lienemann, P., 2010. Thermally-induced transformation of hexabromocyclo dodecanes and isobutoxypenta bromocyclododecanes in flame-proofed polystyrene materials. Chemosphere 80, 701-708.

Heeb, N.V., Schweizer, W.B., Kohler, M., Gerecke, A.C., 2005. Structure elucidation of hexabromocyclododecanes - a class of compounds with a complex stereochemistry. Chemosphere 61, 65-73.

Hu, W., Wang, T., Khim, J.S., Luo, W., Jiao, W., Lu, Y., Naile, J.E., Chen, C., Zhang, X., Giesy, J.P., 2010. HCH and DDT in sediments from Marine and adjacent riverine areas of North bohai sea, China. Arch. Environ. Contam. Toxicol. 59, 71-79.

Kajiwara, N., Sueoka, M., Ohiwa, T., Takigami, H., 2009. Determination of flameretardant hexabromocyclododecane diastereomers in textiles. Chemosphere 74, 1485-1489.

Kajiwara, N., Takigami, H., 2013. Emission behavior of hexabromocyclododecanes and polybrominated diphenyl ethers from flame-retardant-treated textiles. Environ. Sci. Process. Impacts 15, 1957-1963.

Li, H., Zhang, Q., Wang, P., Li, Y., Lv, J., Chen, W., Geng, D., Wang, Y., Thanh, W., Jiang, G., 2012. Levels and distribution of hexabromocyclododecane (HBCD) in environmental samples near manufacturing facilities in Laizhou Bay area, East China. J. Environ. Monit. 14, 2591-2597.

Luo, W., Lu, Y., Wang, T., Kong, P., Jiao, W., Hu, W., Jia, J., Naile, J.E., Khim, J.S., Giesy, J.P., 2013. Environmental concentrations and bioaccumulations of cadmium and zinc in coastal watersheds along the Chinese Northern Bohai and Yellow Seas. Environ. Toxicol. Chem. 32, 831-840.

Marvin, C.H., Tomy, G.T., Armitage, J.M., Arnot, J.A., McCarty, L., Covaci, A., Palace, V., 2011. Hexabromocyclododecane: current understanding of chemistry, environmental fate and toxicology and implications for global management. Environ. Sci. Technol. 45, 8613-8623.

Meng, J., Wang, T., Wang, P., Zhang, Y., Li, Q., Lu, Y., Giesy, J.P., 2015. Are levels of perfluoroalkyl substances in soil related to urbanization in rapidly developing coastal areas in North China? Environ. Pollut. 199, 102-109.

Meng, X.-Z., Duan, Y.-P., Yang, C., Pan, Z.-Y., Wen, Z.-H., Chen, L., 2011. Occurrence, sources, and inventory of hexabromocyclododecanes (HBCDs) in soils from Chongming Island, the Yangtze River Delta (YRD). Chemosphere 82, 725-731.

Meng, X.-Z., Xiang, N., Duan, Y.-P., Chen, L., Zeng, E.Y., 2012. Hexabromocyclododecane in consumer fish from South China: implications for human exposure via dietary intake. Environ. Toxicol. Chem. 31, 1424-1430.

POPRC, 2010. Report of the Persistent Organic Pollutants Review Committee on the Work of its Sixth Meeting: Risk Profile on Hexabromocyclododecane. UNEP/ POPS/POPRC.6/13/Add.2.

POPRC, 2011. Report of the Persistent Organic Pollutants Review Committee on the Work of its Seventh Meeting: Risk Management Evaluation on Hexabromocyclododecane. UNEP/POPS/POPRC.7/19/Add.1.

POPRC, 2012. Report of the Persistent Organic Pollutants Review Committee on the Work of its Eighth Meeting: Addendum to the Risk Management Evaluation on Hexabromocyclododecane. UNEP/POPS/POPRC.8/16/Add.3.

Rani, M., Shim, W.J., Han, G.M., Jang, M., Song, Y.K., Hong, S.H., 2014. Hexabromocyclododecane in polystyrene based consumer products: an evidence of unregulated use. Chemosphere 110, 111-119.

Remberger, M., Sternbeck, J., Palm, A., Kaj, L., Strömberg, K., Brorström-Lundén, E., 2004. The environmental occurrence of hexabromocyclododecane in Sweden. Chemosphere 54, 9-21.

Thanh, W., Han, S., Ruan, T., Wang, Y., Feng, J., Jiang, G., 2013. Spatial distribution and inter-year variation of hexabromocyclododecane (HBCD) and tris-(2,3dibromopropyl) isocyanurate (TBC) in farm soils at a peri-urban region. Chemosphere 90, 182-187.

Tue, N.M., Takahashi, S., Suzuki, G., Isobe, T., Viet, P.H., Kobara, Y., Seike, N., Zhang, G., Sudaryanto, A., Tanabe, S., 2013. Contamination of indoor dust and air by polychlorinated biphenyls and brominated flame retardants and relevance of nondietary exposure in Vietnamese informal e-waste recycling sites. Environ. Int. 51, 160-167.

Vorkamp, K., Rigét, F.F., Bossi, R., Dietz, R., 2011. Temporal trends of hexabromocyclododecane, polybrominated diphenyl ethers and polychlorinated biphenyls in ringed seals from east Greenland. Environ. Sci. Technol. 45, 1243-1249.

Wang, T., Khim, J.S., Chen, C., Naile, J.E., Lu, Y., Kannan, K., Park, J., Luo, W., Jiao, W., Hu, W., Giesy, J.P., 2012. Perfluorinated compounds in surface waters from Northern China: comparison to level of industrialization. Environ. Int. 42, $37-46$.

Weifang Environmental Protection Bureau, 2015. Environmental Impact Assessment Supplementary Report.

Wu, T., Wang, S., Huang, H., Zhang, S., 2012. Diastereomer-Specific uptake, translocation, and toxicity of hexabromocyclododecane diastereoisomers to Maize. J. Agric. Food Chem. 60, 8528-8534.

Xia, C., Lam, J.C.W., Wu, X., Sun, L., Xie, Z., Lam, P.K.S., 2011. Hexabromocyclododecanes (HBCDs) in marine fishes along the Chinese coastline. Chemosphere 82, 1662-1668.

Yu, Z., Chen, L., Maw, B., Wu, M., Sheng, G., Fu, J., Peng, P.A., 2008a. Diastereoisomerand enantiomer-specific profiles of hexabromocyclododecane in the atmosphere of an urban city in South China. Environ. Sci. Technol. 42, 3996-4001.

Yu, Z., Peng, P.a., Sheng, G., Fu, J., 2008b. Determination of hexabromocyclododecane diastereoisomers in air and soil by liquid chromatography-electrospray tandem mass spectrometry. J. Chromatogr. A 1190, 74-79.

Zhang, H., Kuo, Y.-Y., Gerecke, A.C., Wang, J., 2012. Co-release of hexabromocyclododecane (HBCD) and nano- and microparticles from Thermal cutting of polystyrene foams. Environ. Sci. Technol. 46, 10990-10996.

Zhang, Y., Sun, H., Liu, F., Dai, Y., Qin, X., Ruan, Y., Zhao, L., Gan, Z., 2013. Hexabromocyclododecanes in limnic and marine organisms and terrestrial plants from Tianjin, China: diastereomer- and enantiomer-specific profiles, biomagnification, and human exposure. Chemosphere 93, 1561-1568.

Zhu, N., Li, A., Wang, T., Wang, P., Qu, G., Ruan, T., Fu, J., Yuan, B., Zeng, L., Wang, Y., Jiang, G., 2012. Tris(2,3-dibromopropyl) isocyanurate, hexabromocyclododecanes, and polybrominated diphenyl ethers in mollusks from chinese bohai sea. Environ. Sci. Technol. 46, 7174-7181.

Zhu, Z.-C., Chen, S.-J., Zheng, J., Tian, M., Feng, A.-H., Luo, X.-J., Mai, B.-X., 2014 Occurrence of brominated flame retardants (BFRs), organochlorine pesticides (OCPs), and polychlorinated biphenyls (PCBs) in agricultural soils in a BFRmanufacturing region of North China. Sci. Total Environ. 481, 47-54. 